\title{
STUDIES ON PHENYLKETONURIA. I. RESTRICTED PHENYLALANINE INTAKE IN PHENYLKETONURIA 1
}

\author{
By MARVIN D. ARMSTRONG AND FRANK H. TYLER \\ (From the Laboratory for the Study of Hereditary and Metabolic Disorders, and the Depart- \\ ments of Biochemistry and Medicine, University of Utah College of Medicine, \\ Salt Lake City, Utah)
}

(Submitted for publication October 20,1954; accepted December 15, 1954)

The relationship between the biochemical defect in the hereditary condition, phenylketonuria (phenylpyruvic oligophrenia), and the accompanying mental defect is at the present time obscure. The work of Fölling (1) and Jervis $(2,3)$ has shown that the inheritance of the condition appears to be controlled by a single autosomal recessive gene. A series of investigations by Jervis and his collaborators (4-11) has demonstrated that the biochemical defect lies in a failure of the affected individuals to oxidize phenylalanine to tyrosine in the normal fashion. The major abnormal metabolites known to occur in this condition can arise as a logical consequence of the accumulation of large amounts of phenylalanine and the channelling of this phenylalanine into abnormal pathways. These metabolites are phenylalanine itself (8), phenylpyruvic acid (8), phenyllactic acid (8), and phenylacetylglutamine (12). Abnormally high levels of phenylalanine are found in serum (20 to $60 \mathrm{mg}$. per $100 \mathrm{ml}$.) and cerebrospinal fluid (6 to $8 \mathrm{mg}$. per $100 \mathrm{ml}$ ) (9) and phenylpyruvic acid has been demonstrated in the serum of affected individuals (10). Recently it has been found that lesser amounts of other abnormal metabolites are excreted. These include $o$-hydroxyphenylacetic acid $(13,14)$ and products derived from tyrosine $(13,15)$ and tryptophan $(15,16)$. The manner in which these substances arise will be considered in later communications.

According to present concepts of the mechanism of inheritance, single genes are thought to influence single metabolic reactions. Phenylketonuria appears to be the result of a defect in a single gene (3), and the enzyme system concerned appears to be the liver system affecting the oxidation of phenylalanine (11). The mental defect, there-

1 This work was supported by research grants from the National Institutes of Health, U. S. Public Health Service. fore, should follow as a result of this primary biochemical lesion. Several hypotheses might be proposed to explain the mental disorder. These might be grouped into two major categories; one proposing that some substance necessary for normal mental development or function is absent in phenylketonuria, and one that some substance with a toxic effect on the nervous system is produced. It has been suggested that phenylalanine itself, in high levels, might act as a toxic agent (17). Phenylacetic acid, which might be formed from phenylpyruvic acid, has been reported to be toxic to the central nervous system when present in large amounts (18); when phenylacetylglutamine was demonstrated to be excreted in considerable amounts in phenylketonuria, it was suggested that phenylacetic acid might be the agent responsible for the mental defect (12).

The plan of these experiments was to restrict the phenylalanine intake of phenylketonuric patients so that their blood phenylalanine level decreased to an essentially normal value and phenylpyruvic acid excretion decreased to a low amount or vanished. The phenylalanine intake then would be adjusted so that low serum levels would be maintained, and the patients would be observed for a period of several weeks in order to determine whether an objective change in mental ability occurred. It had already been reported that when a low-protein or protein-free diet was fed to a phenylketonuric patient, an immediate lowering of the phenylpyruvic acid excretion occurred, but that phenylpyruvic acid again began to be excreted in considerable amounts as breakdown of tissue protein continued (19). It was apparent, then, that it would be necessary to devise a phenylalanine-low or phenylalanine-free diet. Because most food proteins contain a remarkably uniform amount of phenylalanine (about 4 to 6 per cent) it was necessary to use either a phenylalanine-free 
protein hydrolysate or a synthetic diet in which the protein component was provided by a mixture of pure amino acids. The preparation of a phenylalanineless hydrolysate was feasible, since activated charcoal adsorbs phenylalanine quantitatively from an hydrolysate, but for technical reasons it was preferable to use an amino acid mixture in our initial experiments.

Children were reckoned to be the best potential subjects. In case the mental involvement were progressive and irreversible, a better chance of success in obtaining improved mentality might be expected, and, if any improvement occurred over as short a time as three months, known pathways of child development should make any progress more easily detected in a very young child than in an older individual at a different stage of development.

So far, five children with phenylketonuria have been studied with this restricted regimen. Somewhat equivocal results were obtained with the first two cases, both aged four and one-half years. Therefore, publication of the initial results has been withheld for two years until more definitive information could be obtained. A 13-month old phenylketonuric girl has now been carried for nine months on a restricted diet and has been followed subsequently for 15 months on a normal diet, and two seven-month old infants have been maintained three months. The results from all of these experiments have been strongly indicative that some substance deleterious to the nervous system is present in phenylketonuria and is responsible for some of its pathological manifestations.

After our initial experiments were completed, a report appeared of a similar experiment in which a two and one-half-year old child with phenylketonuria had been given a phenylalanineless casein hydrolysate (20), and recently a personal communication from another group described another such case (21). The results obtained by these workers, although divergent, are essentially in accord with the findings reported here and will be discussed later.

\section{MATERIALS AND METHODS}

The amino acids used in the synthetic diets were obtained from commercial sources and were used without further purification.
Fasting serum levels of phenylalanine were determined by a modification of the method of Kapeller-Adler (22). A trichloroacetic acid (TCA) filtrate of serum was extracted with ether to remove TCA, the aqueous solution was evaporated to dryness on a steam bath, color was developed as described by Block and Bolling (23) and was measured at $540 \mathrm{~m} \mu$ with a Coleman Junior spectrophotometer. Satisfactory recoveries of phenylalanine added to serum were obtained under these conditions. Histidine and tyrosine did not interfere when the color was measured at $540 \mathrm{~m} \mu$ but tryptophan gave rise to an absorbency about the same as that given by phenylalanine. The values for phenylalanine thus actually represent the sum of phenylalanine and tryptophan; error in the estimation of phenylalanine becomes significant only at low levels. The values obtained from a large number of measurements made on fasting normal controls were 3 to $5 \mathrm{mg}$. per $100 \mathrm{ml}$., which is in agreement with the reported average values of $2.0 \mathrm{mg}$. per $100 \mathrm{ml}$. phenylalanine and $1.7 \mathrm{mg}$. per $100 \mathrm{ml}$. tryptophan (combined, $3.7 \mathrm{mg}$. per $100 \mathrm{ml}$.) for fasting human sera (24).

Because of the difficulty of making extended 24-hour urine collections from mentally impaired children, analytical determinations were performed on spot collections of urine. Creatinine was determined by the Jaffé method, total $\mathrm{N}$ by Kjeldahl distillation, and keto acids by a modification of the method of Penrose and Quastel (19). Keto acid excretion is expressed as milligrams of phenylpyruvic acid per inilligram of creatinine. A large number of determinations on different samples from the same individual and on samples from different individuals indicated that this provides a satisfactory measure of the phenylpyruvic acid excretion. The values relating keto acids to total urinary $\mathrm{N}$ and to creatinine were in agreement, so only the values relating the excretion to creatinine are reported here. On Figures 1-5, representative values for keto acid excretion are given at intervals, except during periods when significant changes occurred from day to day, when they are listed daily.

Electroencephalographic measurements were made as frequently as possible with a Grass 8 channel electroencephalograph.

\section{SYNTHETIC DIETS}

These experiments represent the first extended clinical use of synthetic diets, in which the protein component has been supplied in the form of a mixture of pure amino acids. Because of the possibility that other investigators might wish to use similar diets in other types of studies, and because several improvements have been made in compounding and administering these diets during the past $\mathbf{3 0}$ months, a discussion is warranted of the development of the diets currently in use.

The composition of the present amino acid mixture (Table I) differs in several noteworthy respects from the ones first prepared. The first diet used was patterned after those used for animal experiments in this 
TABLE I

Phenylalanine-deficient amino acid mixture

\begin{tabular}{|c|c|}
\hline & gm. \\
\hline \multirow[t]{2}{*}{$\begin{array}{l}D L \text {-Valine } \\
D L \text {-Isoleucine } \\
L \text {-Leucine } \\
D L \text {-Methionine } \\
L \text {-Lysine } \cdot \mathrm{HCl} \\
D L \text {-Threonine } \\
L \text {-Histidine } \cdot \mathrm{HCl} \cdot \mathrm{H}_{2} \mathrm{O} \\
L \text {-Arginine } \cdot \mathrm{HCl} \\
L \text {-Cystine } \\
\text { L-Pyroglutamic acid } \\
L \text {-Asparagine } \cdot \mathrm{H}_{2} \mathrm{O} \\
D L \text {-Alanine } \\
\text { Glycine } \\
L \text {-Tryptophan } \\
L \text {-Tyrosine } \\
\text { (Sodium bicarbonate) }\end{array}$} & $\begin{array}{c}30 \\
30 \\
22 \\
5 \\
20 \\
14 \\
10 \\
10 \\
3 \\
20 \\
20 \\
20 \\
20 \\
0.4 \\
4 \\
10\end{array}$ \\
\hline & 238.4 \\
\hline
\end{tabular}

laboratory (25), and contained all of the commonly occurring amino acids with the exception of phenylalanine, serine, proline, and hydroxyproline. Serine was omitted because of the toxic effects that have been observed when $D L$-serine is given to young rats, and because of the prohibitive expense of $L$-serine; in addition, much recent work has shown that serine may be formed quite rapidly in the presence of an adequate supply of glycine and one-carbon compounds and may also be formed from carbohydrate in the presence of an adequate supply of nitrogen. Proline and hydroxyproline likewise are expensive and are made readily by animals. So far, no deleterious effect of a dietary deficiency of these amino acids has been demonstrated by animal experiments.

Some difficulty was encountered in the early days of the experiments because the patients balked at taking the diet and apparently suffered some nausea. The nausea which occurs after the ingestion of glutamic and aspartic acids in protein hydrolysates and amino acid mixtures has been known for some time. Despite this, it was not considered advisable to omit glutamic acid and aspartic acid from the basal mixtures, because of the central position occupied by glutamic acid in amino acid, carbohydrate, and fat metabolism and its known importance in the metabolism of nerve tissue. Accordingly, the possibility was considered of providing the acidic amino acids in the form of simple derivatives which might not have the bad side-effects of the free amino acids. L-Asparagine was adopted as an economical substitute for aspartic acid, but glutamine is too expensive to be considered as a substitute for glutamic acid. The readily prepared $L$-pyrollidonecarboxylic acid (pyroglutamic acid) was tested as a substitute for glutamic acid and proved to be quite satisfactory. In our experiments there was no indication of a change in nitrogen excretion when it was substituted for glutamic acid, and previous work with animals had already indicated it is absorbed and metabolized to a major extent (26). The incorporation of $L$-asparagine and $L$-pyroglutamic acid in lieu of aspartic acid and glutamic acid eliminated almost completely any noxious taste or nauseating after effects of the amino acid diet, and little trouble has been encountered in administering diets to patients after this change was made.

It should be noted that the amino acid mixture now in use contains a very low amount of $L$-tryptophan, which approximates 0.04 per cent in the total diet, and a small amount of $L$-tyrosine, roughly 0.4 per cent in the complete diet. In the first dietary experiment with Case 1, to be described later, 0.8 per cent of $D L$-tryptophan and 1.0 per cent of $L$-tyrosine were used. In the course of analytical work on urine from this patient, abnormal color reactions were noted; they were found to arise as a result of the use of this amount of $D L$-tryptophan. This observation subsequently led to the identification of abnormal indole acids as constituents of the urine of all patients with phenylketonuria (16). Rather than alter conditions in the middle of the first experiment with Case 1, however, her basal diet was left unchanged throughout its entire course. Case 2, started about four weeks later than Case 1, was given a diet containing 0.1 per cent of $L$-tryptophan, but the same higher level of tyrosine, while Case 3 was given a diet containing 0.04 per cent $L$-tryptophan. After Cases 1 and 2 had been returned to a natural diet and Case 3 had received the low-tryptophan phenylalanine-deficient diet for three months, the alteration to the use of pyroglutamic acid and asparagine in place of glutamic and aspartic acids was made. Further work, carried out toward the end of the experiment with Case 3, demonstrated the presence of elevated amounts of $p$-hydroxyphenyl acids in phenylketonuric urine, so the amount of tyrosine was reduced. Cases 4 and 5 are currently under study and are receiving the amino acid mixture described in Table $I$.

Water-soluble vitamins were prepared as a mixture in Celluflour (Chicago Dietetic Association); this mixture was prepared in bulk (Table II) and stored in the cold. For convenience, a basal dry mix (Table III) sufficient to provide diet for several days was prepared and

TABLE II

Vitamin-Celluflour (B) mixture

\begin{tabular}{|c|c|}
\hline & $g m$. \\
\hline $\begin{array}{l}\text { Riboflavin } \\
\text { Nicotinic acid } \\
\text { Pyridoxine } \cdot \mathrm{HCl} \\
\text { Calcium } d \text {-pantothenate } \\
\text { Thiamine } \cdot \mathrm{HCl} \\
\text { Folic acid } \\
\text { 2-Methylnaphthoquinone } \\
\text { p-Aminobenzoic acid } \\
\text { Biotin } \\
\text { Vitamin } \mathrm{B}_{12} \\
\text { Choline chloride } \\
\text { Ascorbic acid }\end{array}$ & $\begin{array}{c}2.50 \\
10.00 \\
5.00 \\
5.00 \\
2.50 \\
0.50 \\
0.50 \\
10.00 \\
0.050 \\
0.025 \\
150.00 \\
40.00\end{array}$ \\
\hline $\begin{array}{l}\text { Vitamins } \\
\text { Celluflour }{ }^{\circledR}\end{array}$ & $\begin{array}{c}226.075 \\
1000.00\end{array}$ \\
\hline Total & 1226.075 \\
\hline
\end{tabular}


TABLE III

\begin{tabular}{|c|c|c|c|}
\hline Basal dry mix & $g m$. & Basal diet & m./kg./day \\
\hline $\begin{array}{l}\text { Amino acids } \\
\text { Salt mixture } \\
\text { Vitamins- } \\
\text { Celluflour } 8\end{array}$ & $\begin{array}{r}228 \\
44 \\
12 \\
284\end{array}$ & $\begin{array}{l}\text { Basal dry mix } \\
\text { (Protein, estimated } 3.0 \text { ) } \\
\text { Carbohydrate } \\
\text { Fat }\end{array}$ & $\begin{array}{r}4.2 \\
10.0 \\
3.0\end{array}$ \\
\hline
\end{tabular}

stored in the cold. This mixture contained the amino acids, mineral salts (General Biochemicals, Inc., Salt Mixture No. 2), water soluble vitamins, and the small amount of Celluflour included with the vitamin mixture. No apparent deterioration has been detected when this dry mixture has been allowed to stand at room temperature for as long as a year. Fat soluble vitamins were given daily in the form of the usual pharmaceutical preparations.

Diets were compounded in at least five or six portions daily from the basal dry mix, carbohydrate, and fat when they were provided as a slurry to suckling infants. When they were given to older children, the daily diet was prepared as a uniform paste which was stored in the cold and fed in portions. Because of the aim of maintaining low blood levels of phenylalanine, as many feedings as practical were spread throughout 24 hours of a day. Satisfactory quantities as determined in these experiments are given in Table III; individual variations in the demand for amino acids and total calories caused the need for minor adjustments on each patient. Fat was provided as Wesson oil or olive oil to infants suckling a bottle and as a hydrogenated vegetable oil (Spry, Crisco), to older children who ate a paste. Carbohydrate was provided as sucrose or dextrin.

Initial gastrointestinal distress invariably has been encountered for the first few days of the feeding of the synthetic diet. This is manifested as a watery diarrhea accompanied by inflammation and soreness of the perineal region, gas pains, and intestinal cramping. These phenomena usually abated after three to four days. Roughage was provided as Celluflour to meet individual requirements. Usually, about $2 \mathrm{gm}$. per $\mathrm{kg}$. per day is sufficient to allow normal bowel function for children.

Occasionally, children receiving the diets balked at consuming them and showed signs of distress after two to three days. This appeared to occur as a result of an excessive caloric intake and the problem usually could be overcome by reducing the amount of carbohydrate or fat in the diet in order to decrease the caloric intake, which then could be increased gradually to establish an optimal level. It was considered essential to retain a constant intake of amino acids, particularly during the depletion period, in order that breakdown of tissue protein would not lead to an accumulation of excess phenylalanine.

The basal phenylalanine-deficient diet was adhered to rigorously for the initial depletion periods during which the blood phenylalanine levels were lowered. With the first two cases studied, the diet was kept free of natural foodstuffs during most of the experimental period, with the exception of very small amounts of corn starch cookies, prepared as suggested by Rose, Johnson, and Haines (27); these were given frequently between meals along with strained butter and small amounts of clear jelly. Later, small amounts of low protein foods such as strained citrus fruit juices, bananas, apple sauce, cherry syrup, carbonated beverages, etc., were used for flavoring in an attempt to alleviate the bad taste of the amino acid mixture, which at that time contained glutamic acid.

The approximate maximal level of phenylalanine intake above which serum levels began to increase was established by progressively increasing the daily intake of these children. This proved to be about 15 to 20 mg. per kg. per day. For the last three cases studied, an intake of $15 \mathrm{mg}$. per $\mathrm{kg}$. per day has been used and has proved adequate in that this amount allowed the patients to gain weight while still maintaining a low blood level of phenylalanine. With these cases the $15 \mathrm{mg}$. phenylalanine per $\mathrm{kg}$. per day was provided in the form of protein from natural foods. With infants, an appropriate amount of milk (assuming milk to contain approximately 4 per cent protein and milk protein to contain roughly 5 per cent phenylalanine) was used. With older children, small amounts of low-protein baby foods, such as strained applesauce, pears, and peaches and some vegetable preparations were used; in this case the analyses of the foods furnished by the manufacturer were used to approximate the amount of protein in the food and the proteins were assumed to contain 5 per cent phenylalanine. The use of natural foodstuffs in this manner possesses some advantages : first, it has a sparing action on the other amino acids which necessarily accompany the phenylalanine and thus cuts down to some extent the use of the expensive amino acids; second, it provides a more esthetic medium (for the administerer if not the patient) with which to flavor the diets, and finally, it provides more natural roughage than is obtained by the use of Celluflour alone.

\section{EXPERIMENTAL}

When these experiments were undertaken, there was some question as to whether restricting the phenylalanine intake of patients with phenylketonuria would result in a lowering of their levels of blood and tissue phenylalanine to a normal range, or whether they might keep somewhat elevated blood levels, go into negative nitrogen balance, and lose weight. The results obtained with all five cases have been similar: there was no marked loss of weight associated with the administration of restricted diets, blood levels of phenylalanine rapidly came down to a normal range, and the excretion of phenylpyruvic acid ceased within three days after the diet was commenced. The 
data concerning serum phenylalanine levels, urinary excretion of phenylpyruvic acid, phenylalanine intake and weights are presented graphically in Figures 1 to 5, which are included with the appropriate case histories. The excretion of the abnormal metabolites, most of which had not been characterized adequately at the time the first three cases were studied, was followed with the last two cases. It is significant to note here that the excretion of these metabolites decreased to approximately normal amounts as blood levels of phenylalanine approached a normal value; the nature, mechanism of formation, and possible significance of these metabolites will be discussed in detail in later publications.

\section{Case 1}

This patient was a four and one-half-year old girl (Born 11/13/47). She had lived at home until she was admitted to the hospital in May, 1952. Retardation of development was not noted by the parents until she was eight months of age, at which time she was still unable to sit without support. At one year she began to sit up and could use a few words. She learned to walk at two years but did not develop further in language ability and gradually lost the few words she had acquired. Her gait never became normal but was stiff-legged and hypermetric. She had been hyperactive and noisy, frequently banging her head on the wall, slapping her face, voluntarily falling down, biting her tongue, and screaming unintelligibly. There had been no episodes of unconsciousness or convulsions.

Family history: The patient has three sisters. The two eldest are normal. The third child also is a phenylketonuric; she is severely retarded and is confined in a state institution.

Physical examination: T-100 (R); P-104; R-24; BP-106/72; Wt.-17.3 kg.; Ht. $-100 \mathrm{~cm}$. This husky red-headed female child had an extensive, red, scaling dermatitis of the forearms and legs and the characteristic odor of phenylacetic acid. She was extremely hyperactive, her attention passing from one point to another in rapid progression. Her face was round and ruddy in appearance, and her hair was light red in color. She grated her teeth together nearly continually and frequently uttered unrecognizable cries but no words. She was able to walk well, although her movements tended to be hypermetric but not dysmetric. She was able to pick things up and could climb over nearly any obstacle. She responded to attention with grimacing but did not play with toys or feed herself.

General physical examination revealed no positive findings. The skin was fair and soft to the touch except in the areas of dermatitis. The subcutaneous tissue was softer than normal but not otherwise remarkable.
Neurologic examination showed that her muscular tone was somewhat increased generally and that reflexes were hyperactive and equal. Plantar response was flexor. No tremor was present. No objective evidence of sensory impairment was apparent.

Laboratory data: The volume of packed red cells was 38 per cent. The remainder of the usual blood and urine examinations were normal. The Kahn was negative. The acidified urine developed a deep green color on the addition of ferric chloride; the fasting serum phenylalanine level was $42 \mathrm{mg}$. per $100 \mathrm{ml}$.

Chest and skull were normal on X-ray examination. A technically unsatisfactory electroencephalogram showed some slow waves but no seizure discharges; no further electroencephalographic measurements were made.

Hospital course: After an uneventful control period of 10 days during which she gained to $18 \mathrm{~kg}$. on a normal diet, she was placed on an artificial diet in which her protein need was met with the phenylalanine deficient diet. She accepted this poorly and had some watery diarrhea but maintained her weight, until she developed a respiratory infection with low grade fever during the third week. Her weight fell to $16.5 \mathrm{~kg}$. Subsequently, she did well physically.

She refused the diet and remained in a semi-fasting condition from the 8th to the 13th day of the deficient diet. During this period, as would be expected, tissue protein breakdown continued and on Figure 1 it should be noted that sufficient phenylalanine accumulated to raise the serum level from $6 \mathrm{mg}$. per $100 \mathrm{ml}$. to $10 \mathrm{mg}$. per $100 \mathrm{ml}$. Beginning with the fifteenth day her food intake was enforced, and by the 23rd day of the diet she had a serum phenylalanine level of $4 \mathrm{mg}$. per $100 \mathrm{ml}$., an essentially normal level with the analytical method used.

Rather than risk exceeding the amount of phenylalanine she could tolerate, the daily allowance was increased gradually throughout the experimental period. It is evident that only when the amount was increased to 500 mg. per day ( $30 \mathrm{mg}$. per kg. per day) was there a gradual increase in her blood phenylalanine level; in 10 days it had increased from $4 \mathrm{mg}$. per $100 \mathrm{ml}$. to $7 \mathrm{mg}$. per 100 $\mathrm{ml}$. In spite of this rise, phenylpyruvic acid excretion did not recur.

During the first four weeks in the hospital she adapted to the ward situation and showed some improvements in behavior which appeared to be related to the dietary regimen. These consisted of a moderate decrease in the hyperactivity and a considerable increase in her attention span on direct stimulation by an examiner, so that she could be entertained for a period of several minutes. She would also engage in types of continued activity of her own choosing for periods as long as $\mathbf{1 5}$ to $\mathbf{2 0}$ minutes. The dermatitis disappeared after the first week of the diet and her skin remained clear for the remainder of her hospital stay.

For the last eight weeks she appeared to regress, gradually became more hyperactive, her attention span decreased, and at the end of 12 weeks her behavior was very similar to that at the onset of the regimen. When 

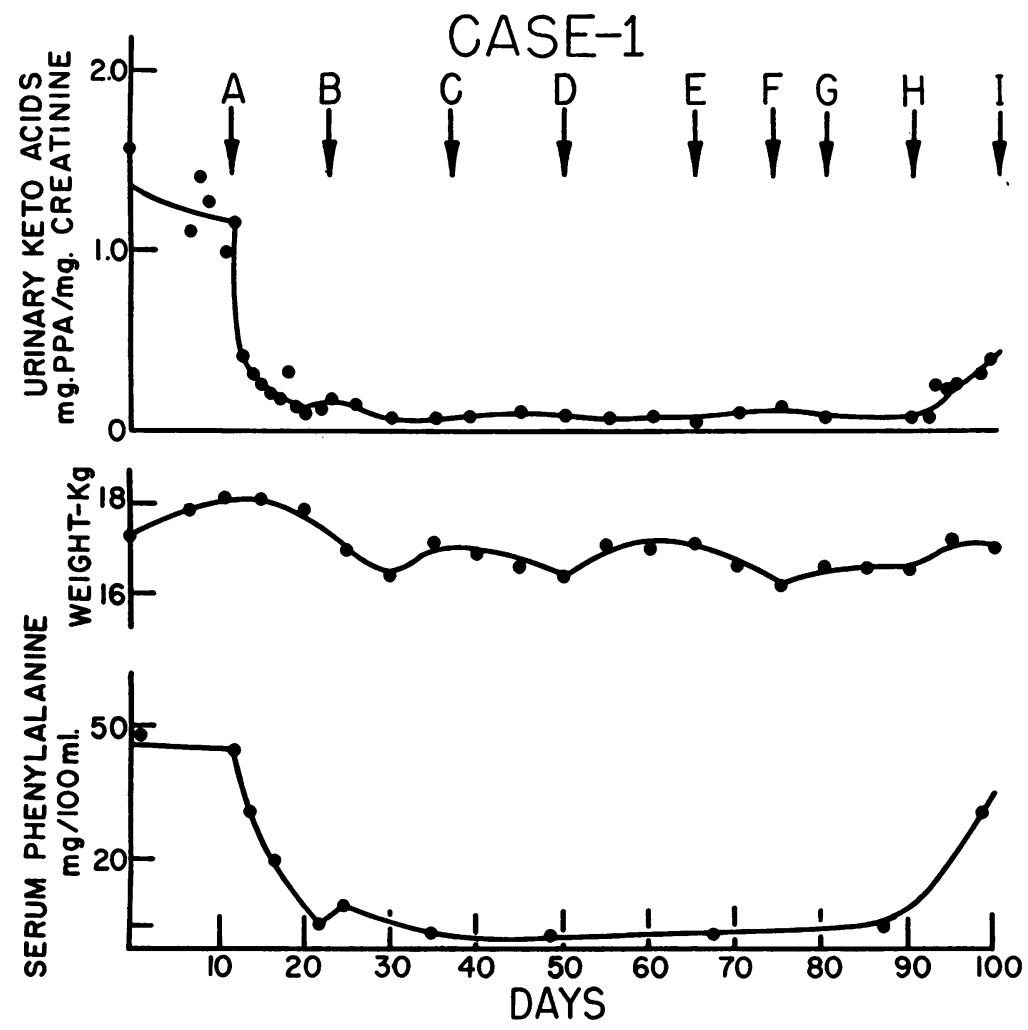

FIGURE 1
A. Phenylalanine-deficient diet initiated
B. $90 \mathrm{mg}$. $L$-phenylalanine daily
C. $100 \mathrm{mg}$. $L$-phenylalanine daily
D. $110 \mathrm{mg}$. $L$-phenylalanine daily
E. $120 \mathrm{mg}$. $L$-phenylalanine daily

she was returned to a natural diet no striking change occurred and she was discharged home.

Course at home: On a natural diet at home her dermatitis recurred. She has continued to grow normally during the following 22 months. She is now a very stout six-year old, who uses a few recognizable words and continues with her marked hyperactivity; her attention span is still limited to a few minutes. She appears to have progressed at about the same relative rate as for the preceding four years.

\section{Case 2}

This patient was a three-year and eleven-month old boy (Born 7/8/48) with extreme mental retardation. He was admitted from the Utah State Training School in June, 1952. He was the product of a normal pregnancy and was thought to be normal during the neonatal period and up to the age of five months. At this time a severe otitis media developed, and subsequent to this period he became obviously retarded. Recurrent "eczema" was a problem at this time. An umbilical hernia was successfully repaired at six months. He failed to learn to sit up. At seven months he began to have seiz-
F. $250 \mathrm{mg}$. $L$-phenylalanine daily

G. $500 \mathrm{mg}$. $L$-phenylalanine daily

H. $1000 \mathrm{mg}$. $L$-phenylalanine daily

I. Natural diet

ures which sometimes extended to clonic movements of the arms and legs. These became progressively more severe and were not controlled hy anticonvulsive medication. He became more retarded and was practically unresponsive, although he continued to take food and grew satisfactorily. He was admitted to the state institution where he was maintained on heavy phenobarbital sedation ( $0.3 \mathrm{gm}$. per day). Although he remained physically well except for an attack of scarlet fever two months before admission, he had led a vegetative existence and never learned to sit up or play. He responded very little to the attendants and continued to have numerous convulsive seizures throughout this period.

Family history: This patient has two siblings with phenylketonuria (Cases 3 and 5) and a normal eightyear old sister. The parents are living and well. Three collaterals of the maternal great-grandmother are known to have been mentally retarded or to have had seizures. Three paternal great-aunts had convulsive disorders and died in infancy.

Physical examination: T-99.4; P-80; R-20; BP$105 / 50$; Wt.-16 kg. This thin, blond, pale-skinned boy was unresponsive to examination or toys. Intermittently 
he developed opisthotonos with irregular clonic movements of the arms and blinking of the eyes. Between episodes he chewed on his arms. The head appeared slightly large for his thin body but the fontanelles were closed and the maximum circumference of the head was only $50 \mathrm{~cm}$. Ear drums showed old scars but no evidence of recent infection. His teeth were small, cone shaped and serrated. The chest was thin with prominent sternum and flaring costal margins. The abdomen showed only a liver palpable $1 \mathrm{~cm}$. below the costal margin. On neurological examination there was increased muscular tone with "cog-wheel" rigidity of arms and legs between periods of seizures. Tendon reflexes were hyperactive but equal. Plantar responses were flexor. No abnormal reflexes were demonstrated. Sensation could not be tested. When frightened, he exhibited an abrupt stiffening with tremors of the extremities, and his skin showed large blotchy red areas. He did not have a dermatitis at this time.

Laboratory data: The usual clinical examination of the blood, urine, and blood chemistry showed no abnormalities. Blood Kahn was negative. Addition of ferric chloride to the acidified urine produced a deep greenish-black color. The fasting serum phenylalanine level was $42 \mathrm{mg}$. per $100 \mathrm{ml}$. Skull roentgenograms showed a relatively small cranial vault with a sloping anterior table. Electroencephalography showed abnormal activity with bursts of diffuse slow waves and periods of petit mal variant activity, most prominently displayed over the occipital lobes.

Hospital course: During the initial two-week period on the ward, the phenobarbital was discontinued. Although he continued to have many convulsive seizures they were less frequent than formerly. $\mathrm{He}$ was somewhat more responsive than he had been previously but continued to be unable to sit up and paid little attention to toys. The experience gained with feeding the first case made possible a more satisfactory initial and continued feeding of the experimental diet to this patient. $\mathrm{He}$ gradually gained weight from a minimum of $14 \mathrm{~kg}$. early in the experimental period to a weight of $17 \mathrm{~kg}$. toward

CASE-2
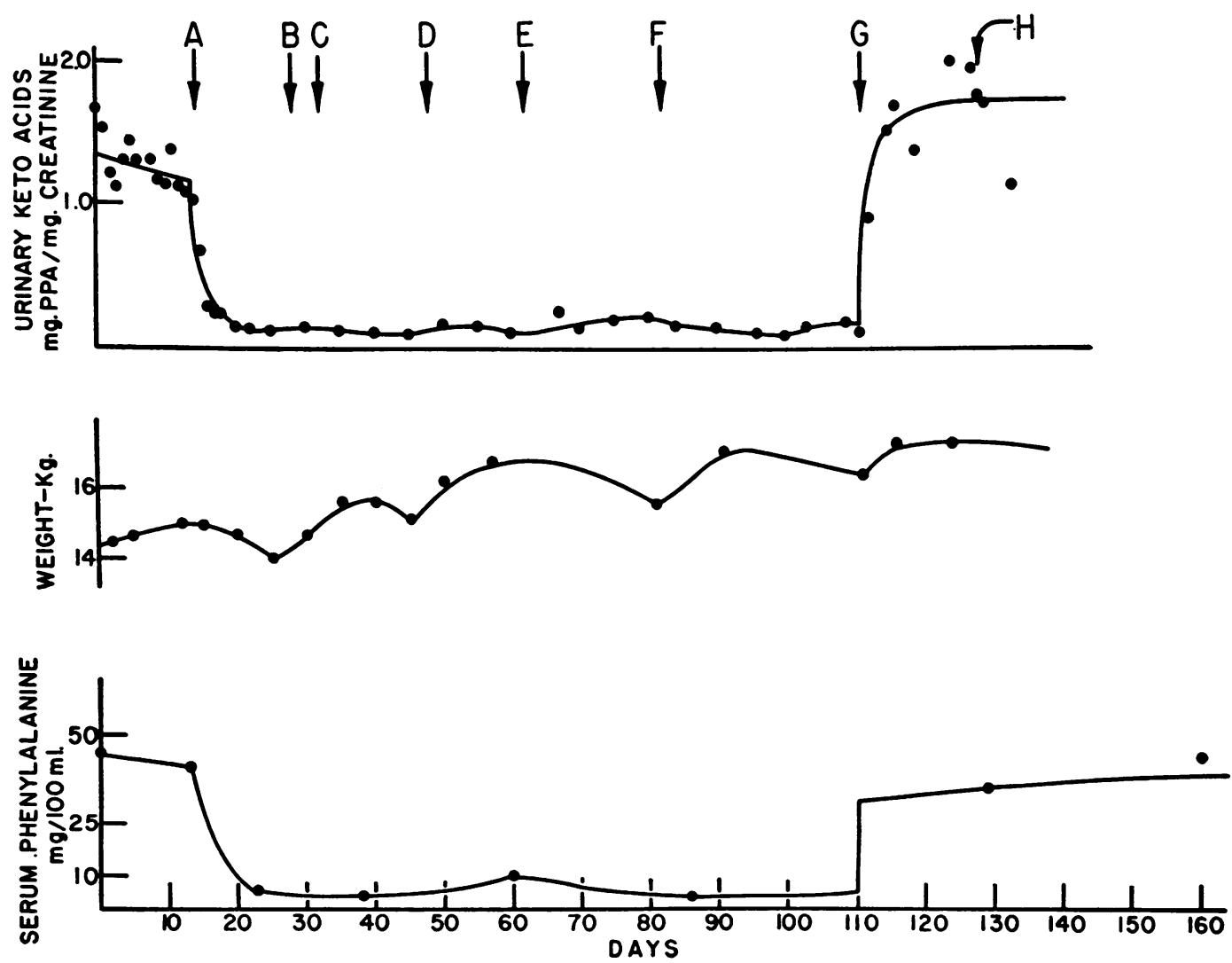

Figure 2
A. Phenylalanine-deficient diet initiated
B. $200 \mathrm{mg}$. $L$-phenylalanine daily
C. $250 \mathrm{mg}$. $L$-phenylalanine daily
D. $300 \mathrm{mg}$. $L$-phenylalanine daily

E. $200 \mathrm{mg}$. $L$-phenylalanine daily

F. $250 \mathrm{mg}$. $L$-phenylalanine daily

G. $2.5 \mathrm{gm}$. $L$-phenylalanine daily

H. Natural diet 
the close; this gain represents an improvement, while receiving the restricted diet, of a malnourished condition which was the consequence of an attack of scarlet fever shortly before he was brought into the metabolic ward. Little experimentation was carried out to determine critically the maximum phenylalanine intake which he could tolerate without increasing his blood phenylalanine levels. It was, however, established that $300 \mathrm{mg}$. per day (19 mg. per kg. per day) was sufficient to cause an increase in blood phenylalanine and that $200 \mathrm{mg}$. (12.5 mg. per kg. per day) allowed a lowering of the increased level. It seems probable that 15 to $17 \mathrm{mg}$. per $\mathrm{kg}$. per day of phenylalanine would have provided an adequate amount of phenylalanine but would not have furnished an excess which could accumulate.

After the experimental diet had been instituted, his seizures disappeared completely and over a period of several weeks he learned to sit up, eventually pulling himself up to the sitting position. He became quite responsive to examiners and nurses and played with toys for brief periods. He remained in this state for the last six weeks of the experimental period. Some decrease in his spasticity was apparent and the $\operatorname{cog}$-wheel rigidity disappeared. The marked stiffening and tremors, as well as the discolored patches of skin which previously were observed when he was frightened were no longer apparent. The seizure pattern had disappeared from his electroencephalogram by the end of the experimental period.

The patient was given the formula with some difficulty and became dehydrated on two occasions with fever. At the end of the experimental period he suffered a respiratory infection of short duration. Phenylalanine was returned to his diet following the oral administration of $2.5 \mathrm{gm}$. of $L$-phenylalanine in a single dose; he showed no immediate or delayed behavioral change but maintained the improvement which had occurred on the diet.

He was given a natural diet and was returned to the state institution, where he remained in much the same state as at the time of his discharge. After he had received a normal diet for four weeks it was quite apparent that the scalp hair which had grown during the time that he was on restricted phenylalanine intake was much darker than that which developed after the experimental period. Seizures with motor manifestations have not recurred either on or off phenobarbital therapy. However, an electroencephalogram made three months after the termination of the experimental regimen clearly showed occasional signs of abnormality, though not extensive, and 20 months later his electroencephalogram again showed seizure activity of moderate severity. At the present time he is considerably less responsive than he was at the end of the experimental period, though he still pulls himself to a sitting position.

\section{Case 3}

This infant girl is a sibling of Cases 2 and 5 and was first seen at the age of 13 months (Born 7/3/51). At that time her mother noted that she had the same odor which had been pointed out to her as occurring with the older child. Pregnancy and delivery were uneventful, except that the patient was born one month prematurely, and weighed only $2500 \mathrm{gm}$. She seemed to be entirely normal during the first months of life. At five months she developed a skin rash which was thought by her pediatrician to be the result of a food allergy. In spite of dietary changes this recurred at intervals. A small umbilical hernia noted shortly after birth had gradually lessened.

Developmentally, she had seemed entirely normal to the parents and pediatrician during the first year. She followed movements with her eyes at one month, sat erect at six months and stood alone and pulled herself erect at 10 months. At one year of age she walked with the support of a chair and said two or three words intelligible to the parents. Consultation with the pediatrician who had followed the child revealed a normal development, with the exception of marked tremulousness of voluntary activity which was prominent at the age of 11 months and was still marked at 13 months.

Physical examination: $\mathrm{T}-98.6^{\circ} ; \mathrm{P}-96 ; \mathrm{R}-22$; Wt. $9.1 \mathrm{~kg}$.; Ht. $-53 \mathrm{~cm}$. The patient was normal in appearance, blond, and fair-skinned. The anterior fontanelle was open, admitting a finger tip. There was a small umbilical hernia which was easily reduced. Over the dorsum of the feet, ankles, and hands there was an eczematoid rash. The patient was able to walk a few steps without assistance. Neurological examination revealed no abnormalities. An abnormal stiffening and tremor of the extremities occurred when she was tired or frightened. The fasting serum phenylalanine level was $42 \mathrm{mg}$. per $100 \mathrm{ml}$.

Course at home: The child was placed on the phenylalanine deficient regimen at home. Considerable difficulty was encountered in maintaining a strict regimen for this ambulatory child in her home environment. In spite of close collaboration with and cooperation from the parents the child occasionally obtained protein food. As can be seen on Figure 3 satisfactorily low blood levels of phenylalanine were not maintained throughout a considerable portion of the experimental period. However, in spite of a higher base line for keto-acid excretion a positive ferric chloride test for phenylpyruvic acid could not be obtained with her urine during the experimental period. This test in our hands has been sensitive to well under $0.01 \mathrm{mg}$. per $\mathrm{ml}$. of phenylpyruvic acid in urine.

Three months after commencing the diet (16 months) the child had learned to walk in typical infant fashion without support and would repeat many words after the parents. She grasped objects accurately with opposed thumb. Reflexes were hyperactive and equal and no spasticity or abnormal pyramidal signs could be demonstrated. She gained to $10.3 \mathrm{~kg}$. She continued on the controlled diet until 22 months of age. At 20 months she had chicken pox with moderate associated rhinopharyngitis and excoriation and superficial infection of the skin lesions. Her respiratory infection continued and at $\mathbf{2 2}$ months she began to vomit the diet and lost weight 

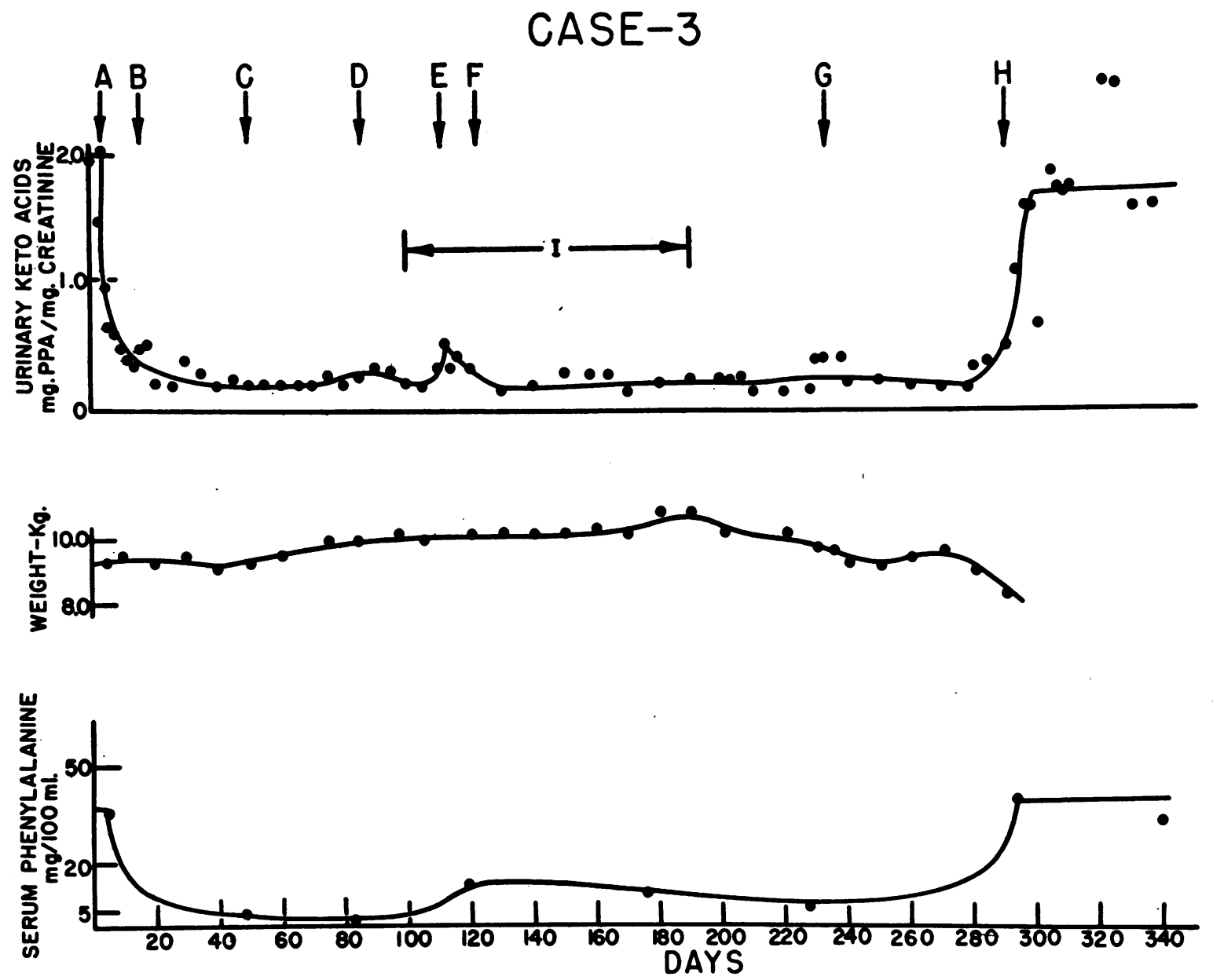

Figure 3
A. Phenylalanine-deficient diet initiated
B. $1.5 \mathrm{gm}$. protein daily
C. $2.5 \mathrm{gm}$. protein daily
D. $3.0 \mathrm{gm}$. protein daily
E. Accidental normal meal

to $8.6 \mathrm{~kg}$. Although these difficulties seemed to be related to the infection and were improving, the parents insisted on returning her to a normal diet. At this time she showed a motor development consistent with her age. She used a number (about 12) of simple words spontaneously but did not form sentences. She identified parts of the body on request. Her mother reported that she played with a doll which she fed $\cdot t$ the table with a spoon from her plate. She was able to put on her shoes but laced them inaccurately. Her gait was "stiff legged" but no spasticity or other abnormal neurologic findings could be demonstrated. One week after she returned to a natural diet she was examined by a psychologist, who used several tests. Her average performance, as well as could be judged, at this time corresponded to that of an 18-month old child (chronological age 23 months, I.Q. 78).
F. $2.0 \mathrm{gm}$. protein daily

G. $3.0 \mathrm{gm}$. protein daily

H. Natural diet

I. Child given jelly beans

When she returned to a natural diet there was no immediate loss of the motor and intellectual abilities which she had attained. She was tested by the same psychologist under the same conditions after a year had elapsed. At this time it was evident that she had not maintained the slightly retarded rate of development she showed a year previously. She was assessed as performing at the level of a 23-month old child (C.A. 35 months, I.Q. 65). She is particularly retarded now in language development. Physical examination reveals slight spasticity and somewhat hypermetric movements suggestive of extra-pyramidal disease, but no other abnormal long tract signs.

\section{Case 4}

This baby girl was first observed in May, 1954 at the age of nine months (Born 8/9/53). She had been followed since November, 1953, by Dr. Robert H. Alway of 
the University of Colorado School of Medicine, where the diagnosis of phenylketonuria was made. She was the result of a normal pregnancy and delivery. At three months of age, following an upper respiratory infection, she had a severe episode of bronchopneumonia with diarrhea and dehydration. During parenteral hydration with sodium bicarbonate solution, she had a convulsion which was clonic and localized on the left side. An elevated spinal fluid protein ( 96 to $136 \mathrm{mg}$. per $100 \mathrm{ml}$.) was observed, but other laboratory data were normal after the initial acidosis and dehydration had been corrected. She developed an anemia which responded to oral iron therapy. When she was five months old the mother commented that she felt the child was retarded and that the diapers had an "unholy-like smell." An extensive dermatitis, most severe in the diaper area, had developed. At that time, she responded poorly to examiners and could not sit alone. She continued to progress physically, but made no developmental progress until she was admitted to the metabolic ward for this study.
Family history: The mother has a severe speech defect. The father and two older siblings are reported to be normal. The urine of the mother and siblings did not give a green color when tested with ferric chloride.

Physical examination: T-98 ; P-110; R-30; Wt.$7.2 \mathrm{~kg}$; Ht. $-61 \mathrm{~cm}$. This was a blond, fair-skinned female infant who lay quietly in bed and was quite oblivious of her surroundings. She appeared to have the physical development of a six-month child. The head was abnormally small $(39 \mathrm{~cm}$. in maximal circumference), and the anterior fontanelle was nearly closed. There was a slight internal strabismus, and the patient did not respond to visual stimulation of any sort. She showed a startle reaction to loud noises and would stop crying when she was patted and bounced. She was unable to sit alone and made no attempt to turn or hold up her head, either prone or when supported in the sitting position. She had frequent episodes of complete unawareness of her surroundings; usually these lasted only a few seconds and were associated with blinking of the eyes but
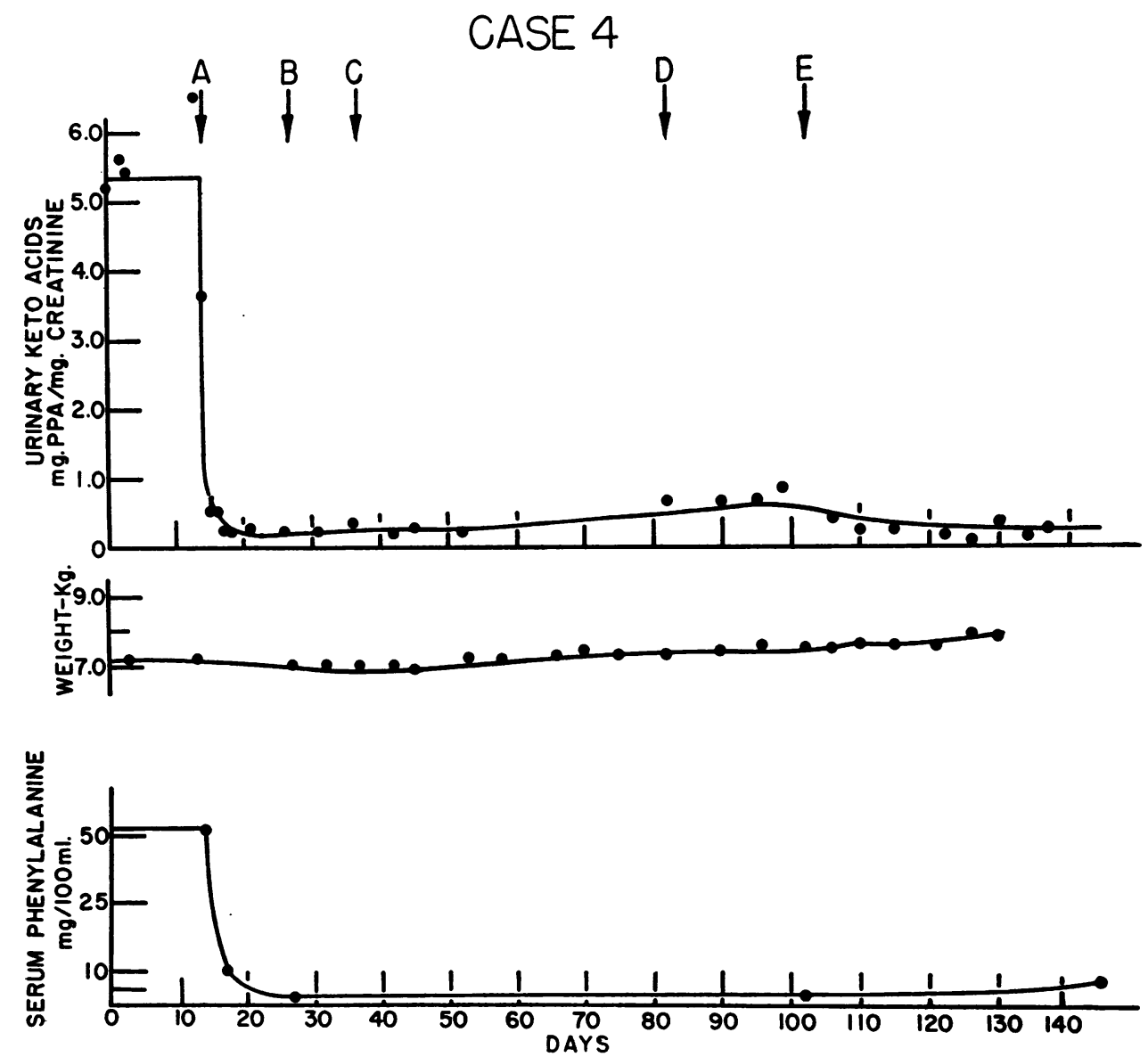

Figure 4

A. Phenylalanine-deficient diet initiated

B. Two gm. protein daily

C. Four gm. protein daily
D. Commence phenylalanine-deficient modified casein hydrolysate in place of amino acids

E. Five gm. protein daily 
no other motor activity. Examination of the lungs, heart and abdomen revealed no abnormalities. The reflexes were hyperactive, particularly in the legs, and the plantar response was extensor bilaterally.

Laboratory data: Except for a hemoglobin of $11.0 \mathrm{gm}$. per $100 \mathrm{ml}$., the routine laboratory examination was not remarkable. Addition of ferric chloride to the acidified urine produced a green color. Her fasting serum phenylalanine level was $53 \mathrm{mg}$. per $100 \mathrm{ml}$. Roentgenograms of the chest were normal. Skull films showed no abnormalities; the sutures were not remarkable. Bone age was equivalent to the chronologic age. The electroencephalogram was grossly abnormal with almost continual bursts of diffuse paroxysmal discharges of high amplitude.

Hospital course: After the infant had been observed for 12 days, the phenylalanine-deficient synthetic diet was instituted. She took the diet well, appeared happy and contented, and suffered no discomfort with the exception of a mild recurrent diarrhea which was controlled by alterations in the Celluflour(B) content of the diet. After two weeks, the frequency of the seizures in the form of lapses of awareness was clearly decreased. The characteristic diffuse bursts of the infantile hypsarhythmic type (28) found in the electroencephalogram became less frequent in records obtained under standard conditions. She appeared to be more responsive to attention, and responded with giggling and cooing. After two months, the clinical evidence of seizure activity had disappeared almost completely and she has had no seizures for the following six weeks. Electroencephalograms still demonstrate seizure discharges, however. After three months of the experimental diet (at twelve months of age), she showed a considerable increase in activity, and was able to roll over and pull herself partially erect and demonstrated improved posture of her head. Her strabismus had disappeared and she responded to visual stimuli, but she did not play with toys or grasp accurately. The restricted regimen is being continued. At the present time, she is still grossly retarded, but appears to have made more progress during the three months on phenylalanine restriction than during the preceding eight months. As nearly as can be judged, she appears to have gained from an approximate mental age of three months to an age of six months during the experimental period.

\section{Case 5}

This boy is a sibling of Cases 2 and 3 (Born 9/2/53). The pregnancy and neonatal course were uneventful. The parents reported he developed normally until April 24, 1954 (seven and one-half months); he had been seen casually by us at intervals throughout his early infancy and had appeared to be developing normally. He had a slight scaling dermatitis. His hair was a dark red color for the first two months, and lightened rapidly to a light blond color during the next three months. The third week in April he appeared to be drowsy and in distress. He was irritable and clutched at his head and left ear. He had his first seizure on April 24; over a period of a week an increasing number of seizures with some motor mani- festations occurred. They were then replaced by an almost continual sequence of seizures in the form of lapses of awareness. According to the parents, the schedule of demonstration of these seizures was similar to that observed with his older brother (Case 2).

Physical examination: This was a pale, blond eightmonth old boy of normal physical development. He was unable to sit. He showed frequent lapses of awareness of one to two minutes in duration, with periods of consciousness of three to five minutes between seizures. There were no motor manifestations. During these episodes his eyes remained open, but did not respond to light, movement of objects, nor did they close when approached closely by an object. His reflexes were very hyperactive and were symmetrical, with patellar and ankle clonus elicitable; plantar response was extensor.

Laboratory data: Routine clinical examination showed no abnormality. The fasting serum phenylalanine level was $63 \mathrm{mg}$. per $100 \mathrm{ml}$. The electroencephalogram was maximally pathological, with closely recurrent diffuse paroxysmal bursts of slow waves of large amplitude, and short periods of damped activity between bursts.

Course at home: He was placed on the synthetic diet at home and has taken this very well. Physical growth and development have continued in a normal pattern, with the exception of a three-week period, during which he became threonine-deficient. This occurred inadvertently when he was transferred from a synthetic diet compounded from pure amino acids to one prepared with a phenylalanine-free casein hydrolysate.

After he had received the phenylalanine-deficient diet for two days he began to have grand mal seizures, rather than the lapses of awareness. He had six or seven of these of moderate duration (two to three minutes) the third day, and they gradually decreased in number each day and in the duration of each attack, until the 22nd day, on which he had no detectable seizure. He continued to have an occasional seizure of 15 to 30 seconds duration until the 33rd day, and had none thereafter. Electroencephalograms were taken frequently during this period, and showed steady improvement until the 33rd day. At this time the electroencephalogram was normal for an infant of his age. His appearance had changed during this time from one of indolence and disinterest to that of a normal alert infant.

After the patient had been seizure-free and with a normal electroencephalogram for 11 days, phenylalanine was returned to the synthetic diet. There was no immediate sign of deterioration, but in the course of the next two weeks he showed increasing signs of distress and irritability. He also demonstrated evidence of neurological impairment. These included pooling of secretions in the pharynx, increased briskness of the tendon reflexes, and manifest patellar clonus. He showed an increasing number of periods of lapses of awareness, resembling those observed when he was first seen. These were different, however, in that they were of shorter duration and he could be aroused from them by sudden noises; he could not be aroused from the similar type of 

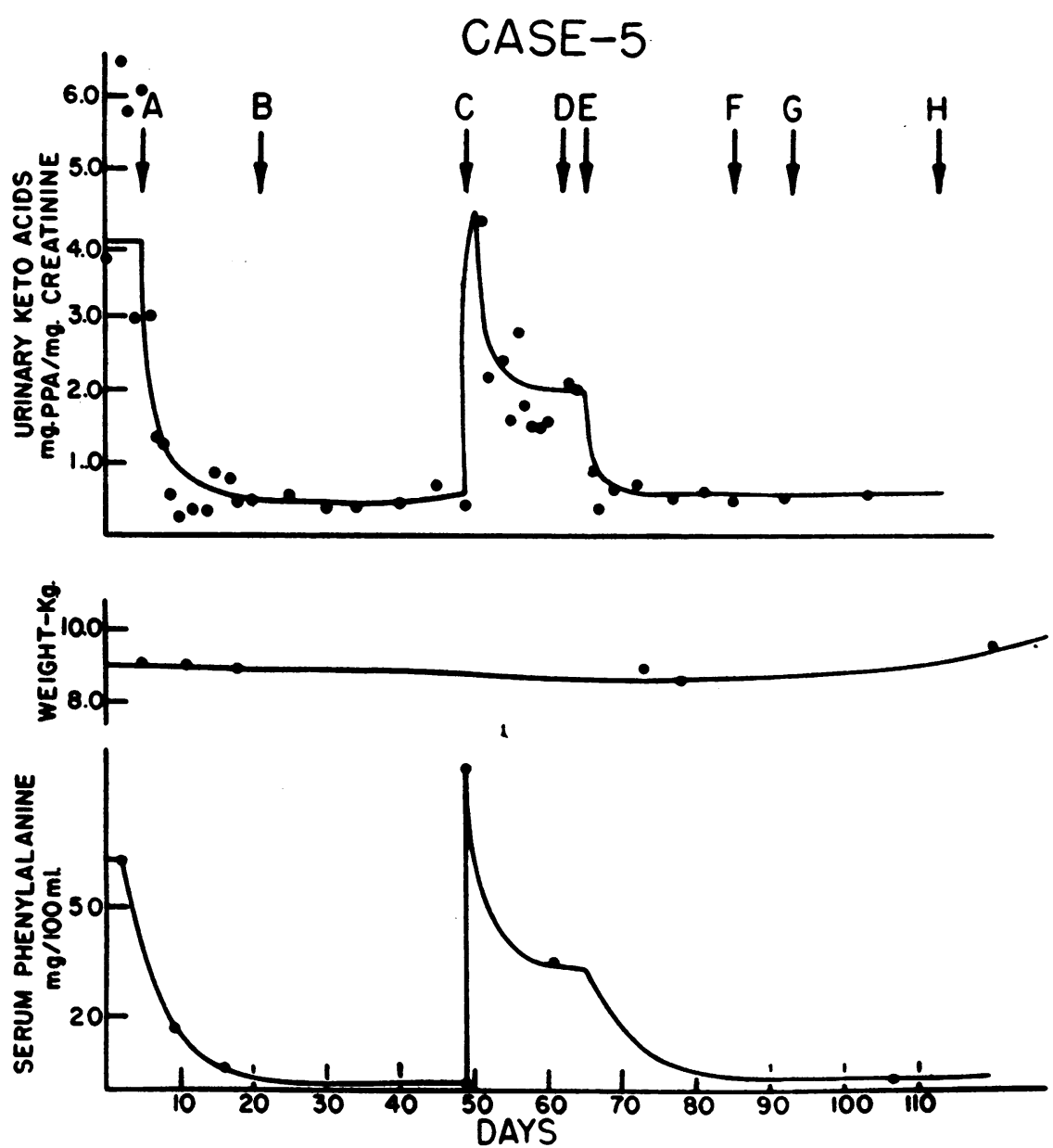

Figure 5
A. Phenylalanine-deficient diet initiated
B. $2.4 \mathrm{gm}$ protein daily
C. $6.0 \mathrm{gm}$. $L$-phenylalanine over 90 minutes, then $\mathbf{8 5 0}$ mg. $L$-phenylalanine daily
D. $1300 \mathrm{mg} . L$-phenylalanine daily

seizure occurring at the beginning of the experimental period. An unexpected finding was that his electroencephalogram remained normal throughout this period!

In order not to risk the possibility of permanent damage to this infant, he was returned to the deficient regimen after he had received phenylalanine for 16 days. ${ }^{2}$ At the present time (12 months of age) he is able to stand with support but does not pull himself erect. He grasps with fair accuracy, using an opposed thumb, and examines objects briefly before discarding them or plac-

2 At this time he was given a basal diet made up from a phenylalanine-free casein hydrolysate, which was also devoid of tyrosine, tryptophan, glutamic acid and aspartic acid. The hydrolysate was supplemented with amino acids to make it approximate in composition the basal amino acid mixture listed in Table I.
E. Phenylalanine-deficient modified casein hydrolysate

F. $2.4 \mathrm{gm}$. protein daily

G. $3.6 \mathrm{gm}$. protein daily

H. $4.8 \mathrm{gm}$. protein daily

ing them in his mouth. He makes various sounds but has no recognizable words. Overall, his developmental age appears to be about two months behind his chronological age, and he seems to have progressed at nearly a normal rate following the delay occasioned by his illness at seven months of age. It is planned to continue providing him with the diet for as long as possible.

\section{DISCUSSION}

Restriction of the phenylalanine intake of these patients with phenylketonuria led to a lowering of their blood levels of phenylalanine to normal values. Their excretion of phenylpyruvic acid ceased when the serum phenylalanine fell below 15 to 17 mg. per $100 \mathrm{ml}$. and the amounts of the minor 
abnormal metabolites, $o$-hydroxyphenylacetic acid, $p$-hydroxyphenyllactic acid, $p$-hydroxyphenylacetic acid, indolelactic acid, and indoleacetic acid which were excreted, decreased to approximately normal as the serum phenylalanine reached a normal level. When phenylalanine was returned to their diets the high blood level of phenylalanine was restored immediately, and the abnormal metabolites again began to be excreted. Thus, the prominent biochemical abnormalities which characterize the condition were corrected by this regimen.

The changes in the mental and neurological status of the patients were not so definite, but several conclusions concerning the nature of the mental defect occurring in phenylketonuria may be drawn as a result of the observations presented here. First, it is apparent that the oligophrenia in phenylketonuria does not occur simply as a result of a functional interference in an otherwise normal brain either by the presence of excessive amounts of phenylalanine or by any of the abnormal metabolites which are formed as a consequence of its presence. None of the four patients who have been given a restricted regimen followed by a return to normal phenylalanine intake and the resulting high blood levels of this amino acid showed any immediate signs of a marked deterioration when phenylalanine was returned to their diet, in spite of the prompt recurrence of the biochemical anomalies. A marked and immediate regression certainly should have been expected if the mental symptoms were the result of inhibition of normal mental functioning in an otherwise normal central nervous system. In addition, Case 1 had demonstrated little change in behavior at the end of three months of the restricted regimen.

Improvement in some clinical aspects was observed, however, in each of the five cases studied, while they were receiving the synthetic diet. It seems certain that at least some of the pathological manifestations of phenylketonuria result because of the presence in affected individuals of some substance or substances with a detrimental effect upon the nervous system. This was particularly evidenced by the control of convulsions when they were present. With Case 5 , a severe convulsive disorder was controlled within three weeks after the beginning of a phenylalanine-low diet. Also, with Case 2 seizures were eliminated and seizure discharges disappeared from the electroencephalo- gram during the three months of the restricted diet. Overt signs of epileptic seizures were eliminated in Case 4, although she still has a very abnormal electroencephalogram after three months. It seems likely that the clinical improvement observed in these three cases may have followed the correction of the grossly abnormal electrical activity of their brains. Other less objective signs which indicated a removal of some toxic agent in the patients studied included the disappearance or improvement of signs of neurological abnormality, elimination of the characteristic dermatitis found in phenylketonuria, an increased response to environmental stimuli, and a prolonged attention span. It should be emphasized here that no improvement would be expected if the pathological symptoms occur because of the lack of some essential substance; this regimen could not have provided a missing substance, but could have decreased the amount of an abnormal toxic substance. The slower rate of progress of Case 3 after she was returned to a natural diet is probably significant in indicating that she may have been protected from deterioration while she was receiving the restricted diet.

It seems probable that unknown and possibly complex factors other than the known defect in phenylalanine oxidation operate in conjunction with it and contribute to the mental defect. This is consistent with the findings of previous workers, who did not observe any difference in phenylalanine metabolism that could be related to the degree of mental defect, despite wide variations in the degree of mental impairment (9). The biochemical observations did not reveal any significant differences among any of the five patients studied in this work, yet there were marked differences in their clinical condition. This was particularly marked in the case of the two infants. Case 5 progressed in an apparently normal fashion until he was seven months old, while Case 4 was markedly retarded from a very early age, perhaps from birth. Case 3, who appeared at 13 months to be normal in physical and mental development, showed the same typical pattern of high blood phenylalanine and high urinary phenylpyruvic acid excretion as the other patients, including her brothers, Cases 2 and 5 . Studies on the other abnormal metabolites excreted by these patients have failed to demonstrate any significant difference 
between severely affected and slightly affected patients.

After the experiments were completed with the first three patients reported here, a description of a similar experiment was made by Bickel, Gerrard, and Hickmans (20). These investigators fed a diet containing a phenylalanineless casein hydrolysate to a severely affected two-year old phenylketonuric child. They reported a significant improvement in her condition over a period of several months. She took an interest in her surroundings, and developed much improved motor abilities. When 4 to $5 \mathrm{gm}$. of phenylalanine was added to the diet each day a prompt and striking regression to her earlier status occurred. The authors note, however, that, as in the case with our experimental subjects, it was difficult to make a critical assessment of the child's mental progress.

Recently, a communication from another British group (21) also reported a dietary experiment with a phenylketonuric child. Their two-year old patient was given a well-defined diet in which the nitrogen was provided in the form of pure amino acids, and the blood phenylalanine was maintained at a normal level (1.5 mg. per $100 \mathrm{ml}$.) for six months. No unambiguous changes in the patient's condition, objectively or subjectively, were observed, nor was there a change when phenylalanine was returned to the diet. The apparent discrepancy between the results of the British groups as well as the differences observed in our phenylketonuric patients may, however, only point to the complexity of the problem of relating the mental defect to the inherited defect in the metabolism of phenylalanine.

Whether the administration of diets restricted in phenylalanine will provide an effective therapeutic measure for phenylketonuria will await much further experimentation before any positive conclusions can be made. The results of our experiments may be interpreted as indicating that such diets are probably beneficial, particularly when a convulsive disorder is present. At the present time, however, it appears that such a regimen must be initiated at a very early age and very soon after the onset of pathological symptoms, to prevent permanent damage to the central nervous system. It might be speculated that the different experiences reported here with Cases 4 and 5 , both of whom were started on a restricted diet at about the same age and who had the same outward signs of clinical involvement at the time they were first observed, occurred because Case 4 had been severely affected for at least six months, while Case 5 was given a restricted diet within three weeks after the onset of pathological symptoms. Permanent damage may have occurred to Case 4 during the longer period during which she suffered severe retardation of development.

That benefit can be derived from restricting the phenylalanine intake of phenylketonuric infants is well shown by Case 5, who is at present doing well. A control of sorts on this infant is provided by his older sibling, Case 2 . The children bear a strong familial resemblance to each other, and both showed a nearly normal development until the age of six or seven months. At this time, both suffered the onset of a convulsive disorder, which continued unabated in Case 2 for several years, and which was completely controlled in Case 5 after he had received a phenylalanine-deficient diet for only three weeks.

Another point that remains to be settled is whether continuation of the dietary regimen will benefit patients who do not show an immediate apparent response. If the mental defect occurs primarily because of a lack of development of the brain rather than as the result of permanent damage, it is reasonable to conclude that the relatively short term experiments reported with four of our cases may not have been sufficiently long for the manifestation of a developing mentality. Further long term and well-controlled experiments with older children will need to be carried out to gather information in this connection.

\section{SUMMARY}

1. Well defined synthetic diets, in which the protein portion is composed of pure amino acids, have been prepared for use in clinical experiments.

2. Five children with phenylketonuria have been given synthetic diets deficient in phenylalanine. Blood phenylalanine levels were lowered to normal values, phenylpyruvic acid excretion ceased, and abnormally high excretion of other metabolites ceased. The children were maintained in this condition for varying lengths of time.

3. A four and one-half-year old girl demonstrated some behavioral improvement after four 
weeks of this treatment and regressed to her original condition after three months.

4. A four and one-half-year old boy showed considerable improvement in behavior and in neurological status. The occurrence of frequent seizures ceased and seizure activity disappeared from his electroencephalogram. He did not revert to his previous condition rapidly when phenylalanine was returned to his diet, but deteriorated slowly.

5. A 13-month old girl, who was nearly normal in development, continued to develop at the same rate for nine months while receiving a phenylalanine-deficient diet. She has matured mentally more slowly during the 15 months following the return of phenylalanine to her diet.

6. A 10-month old girl was relieved of seizures, although her electroencephalogram has not become normal. She has developed much more rapidly while receiving the diet for three months than she had previously.

7. Almost continuous epileptiform seizures in an eight-month old boy were controlled completely and his electroencephalogram became normal after he had received the restricted diet for three weeks. When phenylalanine was returned to his diet for two weeks he did not show a recurrence of the seizures, but demonstrated signs of distress and of neurological impairment. At present he is continuing to develop normally on the diet.

8. All the observations made on the patients with phenylketonuria studied are consistent with the hypothesis that the effects of some detrimental substance on the central nervous system have been overcome by the use of the phenylalanine-restricted diet. It seems probable that such diets should be initiated at a very early age in order to prevent irreversible damage to the central nervous system.

\section{ACKNOWLEDGMENTS}

It gives us pleasure to acknowledge the encouragement and assistance of Professor M. M. Wintrobe, without which this research would not have been possible.

We are grateful to Winthrop-Stearns, Inc., for the gift of generous quantities of amino acids, which provided the major portion of the diets used in these experiments, to Merck and Co., Inc., for the donation of some amino acids, vitamins, and a phenylalanine-free casein hydrolysate, and to the Dow Chemical Company and the Mann Chemical Company for other amino acids. The Gerber Products Company provided generous supplies of canned baby foods, which were used in these experiments. We wish to thank Dr. E. E. Howe, Merck and Co., Inc., for his interest in this work and for the development of the phenylalanine-free casein hydrolysate which is being used at the present time.

We are especially indebted to Dr. R. H. Alway, Professor of Pediatrics, University of Colorado School of Medicine, who observed and made the diagnosis of phenylketonuria for Case 4 at the age of five months, and arranged to make her available for our current study and for a long-term continuation of the dietary regimen with her.

Dr. James F. Bosma, Professor of Pediatrics, University of Utah College of Medicine, provided invaluable assistance in assessing the status of the infants under study at present and in interpreting the electroencephalograms made on all the patients.

We are grateful to Dr. Mark Allen, Psychologist for the Utah State Training School, for his assistance in the psychological assessment of Case 3, and to Dr. V. F. Houston, Director, and the staff of that institution for their assistance in follow-up studies of Case 2.

We are indebted to Drs. A. A. Sandberg, A. Florentine, and H. Castle, Fellows in Medicine, and to the resident and nursing staff for their aid in caring for patients in the metabolic ward, to Kathryn S. Robinson and Patricia Wall for performing the analytical work, and to Jacqueline Parker, who carried out the daily preparation and feeding of diets to patients in the metabolic ward.

\section{REFERENCES}

1. Fölling, A., Ueber Ausscheidung von Phenylbrenztraubensäure in den Harn als Stoff wechselanomalie in Verbindung mit Imbezillität. Ztschr. f. physiol. Chem., 1934, 227, 169.

2. Jervis, G. A., Phenylpyruvic oligophrenia; Introductory study of fifty cases of mental deficiency associated with excretion of phenylpyruvic acid. Arch. Neurol. \& Psychiat., 1937, 38, 944.

3. Jervis, G. A., The genetics of phenylpyruvic oligophrenia. (A contribution to study of the influence of heredity on mental defect.) J. Ment. Sc., 1939, $85,719$.

4. Jervis, G. A., Metabolic investigations on a case of phenylpyruvic oligophrenia. J. Biol. Chem., 1938, 126, 305.

5. Jervis, G. A., Block, R. J., Bolling, D., and Kanze, E., Chemical and metabolic studies on phenylalanine; II. The phenylalanine content of the blood and spinal fluid in phenylpyruvic oligophrenia. J. Biol. Chem., 1940, 134, 105.

6. Block, R. J., Jervis, G. A., Bolling, D., and Webb, M., Chemical and metabolic studies on phenylalanine; III. The amino acid content of tissue proteins of normal and phenylpyruvic oligophrenic individuals. A note on the estimation of phenylalanine. J. Biol. Chem., 1940, 134, 567.

7. Jervis, G. A., Studies on phenylpyruvic oligophrenia. The position of the metabolic error. J. Biol. Chem., 1947, 169, 651. 
8. Jervis, G. A., Excretion of phenylalanine and derivatives in phenylpyruvic oligophrenia. Proc. Soc. Exper. Biol. \& Med., 1950, 75, 83.

9. Borek, E., Brecher, A., Jervis, G. A., and Waelsch, H., Oligophrenia phenylpyruvica. II. Constancy of the metabolic error. Proc. Soc. Exper. Biol. \& Med., 1950, 75, 86.

10. Jervis, G. A., Studies on phenylpyruvic oligophrenia. Phenylpyruvic acid content of blood. Proc. Soc. Exper. Biol. \& Med., 1952, 81, 715.

11. Jervis, G. A., Phenylpyruvic oligophrenia deficiency of phenylalanine-oxidizing system. Proc. Soc. Exper. Biol. \& Med., 1953, 82, 514.

12. Woolf, L. I., and Vulliamy, D. G., Phenylketonuria with a study of the effect upon it of glutamic acid. Arch. Dis. Childhood, 1951, 26, 487.

13. Boscott, R. J., and Bickel, H., Detection of some new abnormal metabolites in the urine of phenylketonuria. Scandinav. J. Clin. \& Lab. Invest., 1953, 5, 380.

14. Armstrong, M. D., Shaw, K. N. F., and Robinson, K. S., Studies on phenylketonuria II. The excretion of $o$-hydroxyphenylacetic acid in phenylketonuria. J. Biol. Chem., In press.

15. Armstrong, M. D., and Robinson, K. S., Abnormal metabolites in phenylketonuria. Federation Proc., 1954, 13, 175.

16. Armstrong, M. D., and Robinson, K. S., On the excretion of indole derivatives in phenylketonuria. Arch. Biochem. \& Biophys., 1954, 52, 287.

17. Rimington, C., Diet and inborn errors of metabolism. Brit. J. Nutrition, 1950, 4, 242; The interpretation of biochemical detail revealed by inborn errors. Biochem. Soc. Symposia, 1950, No. 4, 16.
18. Sherwin, C. P., and Kennard, K. S., Toxicity of phenylacetic acid. J. Biol. Chem., 1919, 40, 259.

19. Penrose, L., and Quastel, J. H., Metabolic studies in phenylketonuria. Biochem. J., 1937, 31, 266.

20. Bickel, H., Gerrard, J., and Hickmans, E. M., The influence of phenylalanine intake on the chemistry and behavior of a phenylketonuric child. Acta pediat., 1954, 43, 64 .

21. Dent, C. E., Personal communication, June, 1954.

22. Kapeller-Adler, R., Ưber eine neue Reaktion zur qualitativen und quantitativen Bestimmung des Phenylalanins. Biochem. Ztschr., 1932, 252, 185.

23. Block, R. J., and Bolling, D., The Amino Acid Composition of Proteins and Foods; Analytical Methods and Results. Springfield, Charles C Thomas, 2nd ed., 1951, p. 139.

24. Harper, H. A., Hutchin, M. E., and Kimmel, J. R., Concentrations of nineteen amino acids in plasma and urine of fasting normal males. Proc. Soc. Exper. Biol. \& Med., 1952, 80, 768.

25. Armstrong, M. D., and Lewis, J. D., The toxicity of $o$ - and $p$-fluorophenyl- $D L$-alanines for the rat. J. Biol. Chem., 1951, 188, 91.

26. Pedersen, S., and Lewis, H. B., The partition of urinary nitrogen after the oral administration of glutamic acid, pyrrolidonecarboxylic acid, proline, and hydroxyproline to rabbits. J. Biol. Chem., 1944, 154, 705.

27. Rose, W. C., Johnson, J. E., and Haines, W. J., The amino acid requirements of man. I. The rôle of valine and methionine. J. Biol. Chem., 1950, 182, 541.

28. Gibbs, F. A., and Gibbs, E. L., Atlas of Electroencephalography, vol. 2, Epilepsy. Cambridge, Mass., Addison-Wesley Press, Inc., 1952, p. 24. 